\title{
Bionics and the choice of rational structural form
}

\author{
Irina Mayatskaya ${ }^{1}$, Victor Eremin ${ }^{1, *}$ \\ ${ }^{1}$ Don State Technical University (1, Gagarin sq., Rostov-on-Don, 344000, Russia)
}

\begin{abstract}
The work is devoted to the development of such an interesting topic as bionics. The relevance of the study of this topic is due to the processes taking place both in our country and in the world. The aim of the work is to study the laws of formation of living organisms, their structure, design features, principles of operation and the use of this knowledge in the design of structures and constructions. The paper considers different areas of bionics and analyzes bionic principles. Particular attention is paid to architectural bionics in terms of the choice of optimal design. The study of natural objects allows creating structures and constructions that take into account properties, shape, structure, organization of life of living organisms and plants. The issues of creation of an optimum design are considered. To do this, it must have the following properties: reliability, durability, efficiency, maintainability, and of course, environmental friendliness. The paper provides the analysis of trends in bionics. It is worth noting that these trends are penetrating each other, creating a new one. The examples of constructions based on bionic principles are given. To solve this problem, it is necessary to apply methods of mathematical modeling. They allow choosing the best option using a numerical experiment. The results of the analysis of the problem can be used in the design of structures and constructions of unique structures, and should serve the further development of bionic science. The combination of bionic principles and optimization methods creates the basis for such developments.
\end{abstract}

\section{Introduction}

The interest in the problem of bionic research is caused by the fact that recently this concept of "bionics" has been very often found in technical literature and in architectural projects [1-4].

The designers have always faced the choice of optimal design. Recently much attention has been paid to the creation of such structures, which used the principles of bionics. Constructive systems of living organisms and plants are considered from the point of view of creation of constructions and structures in which one or another of their properties is considered that does the created projects unique and optimum. It should be noted that materials and composite elements are used with the use of certain qualities of natural objects $[5,6]$.

\footnotetext{
* Corresponding author: eremin.vd@yandex.ru
} 
Shells and skulls of some objects of animal world are very strong structures (Fig. 1). Their layered structure determines the most rational distribution of stresses arising in the structure under the influence of the applied load.

a)

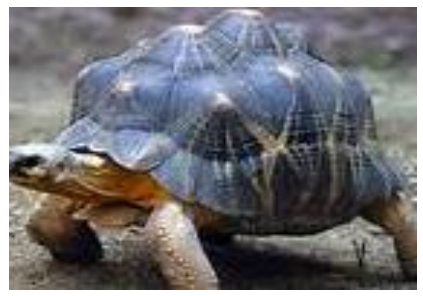

c)

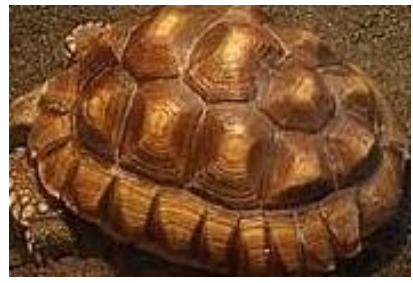

b)

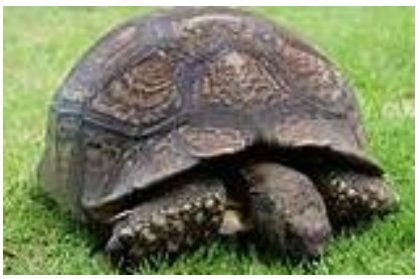

Fig. 1. Turtles with different forms of shells: a) in the form of cones; b) in the form of flat shells; c) in the form of hexagonal pyramids.

The study of wildlife objects will reduce the weight of structures and optimize the structure itself. Optimal forms require a minimum of material and energy resources. Application of methods of mathematical modeling allows you to see a variety of combinations of different qualities of the design and materials used.

It is necessary to pay attention to such direction as architectural bionics. We would like to mention the creation of structures based on bionic principles and their experience in the practice of construction and creation of technical complexes.

It is not acceptable to simply copy the structure of a natural object for the design in question. It is necessary that it is reliable and have those operational properties necessary for this purpose. Therefore, the use of natural structure can be considered only as a stage of optimal design [7-12].

The perfect forms are created by nature. Architects turned their attention to the perfection of forms created by nature and the functionality of organisms, which is also used in the design of structures. Bionics is the use of principles and methods of organization of living organisms and natural structures in the design of structures in terms of harmony and rationality [7, 1012].

The main objective is to study the laws of formation of living organisms, their structure, design features, principles of operation in order to use this knowledge in design.

To create an optimal design, it is necessary that it has the following properties: reliability, durability, efficiency, maintainability, and of course, environmental friendliness. To solve this problem, the methods of mathematical modeling are used, which allow you to choose the optimal option by means of numerical experiment.

Bionics is characterized by direct study of natural objects and transfer of more rational solutions to the designed construction; creation of a design with modeling of stages of living objects development, improving the shape, structure and processes; creation of robotic systems based on bionic principles.

But the last direction in the article will not be considered. These trends are currently receiving special attention and represent an independent trend.

In wildlife, the possibility of obtaining optimal design is wider due to the diversity of natural objects and their changes over time. Living organisms of both flora and fauna have 
the strength of rigidity, stability and high bearing capacity. This is due to the principle of constancy of structures, forms and constructions through the functions of natural objects.

The structure of constructions of natural objects are connected with finding the optimal solution based on the principle of minimizing the mass and the choice of rational form and structure.

Let us consider what panels were used in the early days of aircraft industry. The designers began to use layered shells and plates with a light intermediate layer, and then they began to use panels with an aluminum cellular intermediate layer. Currently, layered shells with a cellular intermediate layer of polymer composite materials are used. This solution makes the structure more durable and lightweight.

Fig. 2 presents cellular structures.

a)

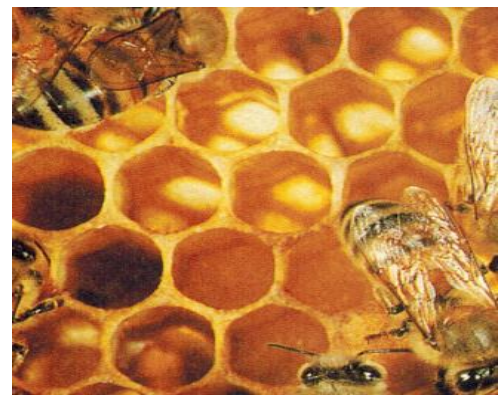

b)

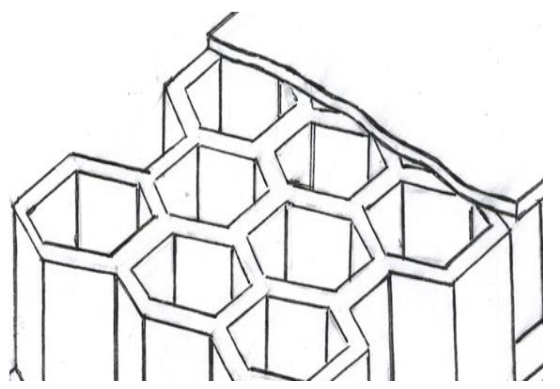

Fig. 2. Cellular design: a) honeycomb, b) plate with a cellular intermediate layer.

The principle of the directional form of stability loss of the elements that are pre-curved in accordance with the curved centerline corresponding to a stable curvilinear form of equilibrium. The use of grid shells with an orthogonal lattice or with a spiral arrangement of elements in space allows you to create a strong and stable structure.

Shabolovka radio-television tower is called a hyperboloid of V. G. Shukhova (Fig. 3). This light, openwork structure is a model of the structure built on the basis of bionic approach.

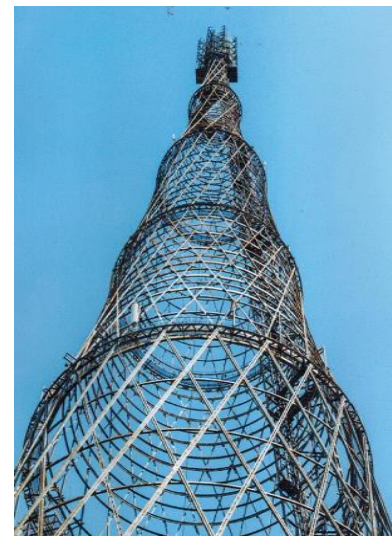

Fig. 3. Design of a hyperbolic shape (Shukhov tower).

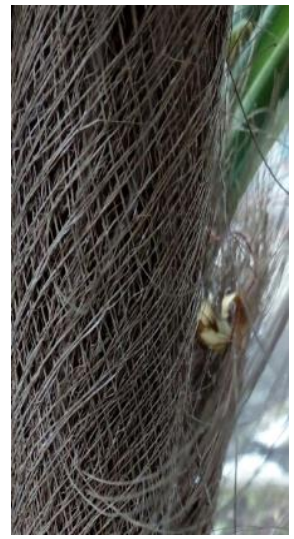

Fig. 4. A fragment of the trunk of a palm tree.

Bionic approach is an art of applying the laws of wildlife structure for non-biological purposes, in this case, in construction. If you look at the plant objects (Fig. 4) where the fibers are a structure of intertwined strands, it can be seen that they resemble a combination of tower rods. 
Bionics studies the structure of natural objects that can be used to create new materials and composite structures. Fig. 5 shows natural objects with high strength.

a)

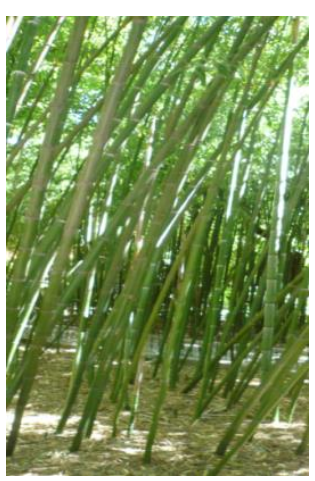

b)

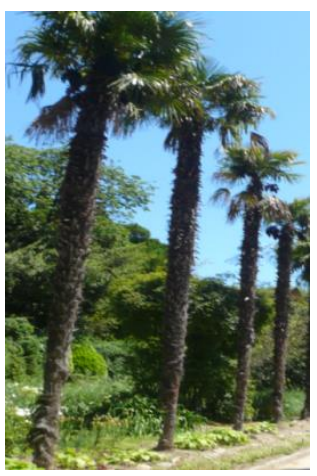

c)

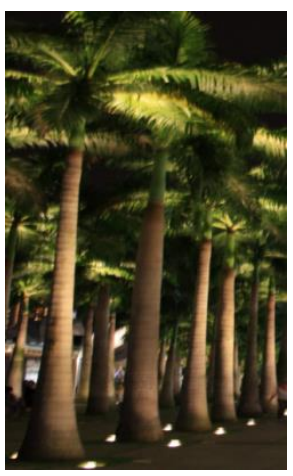

Fig. 5. Plants with high strength: a) bamboo; b) palm tree with a trunk of constant cross-section; c) palm tree with a trunk of variable cross-section.

However, in the implementation of these projects, the optimal solution is chosen while minimizing both material costs and energy resources. This is the principle of achieving maximum effect at minimum cost.

An example of an object construction using the structure of plant stems or tree trunks is Ostankino Tower, Moscow, presented in Fig. 6, A. The designer found the optimal orientation of the cables and the structure of the construction. However, also another form of structures (Fig. 6, b, c) is used for the construction of TV towers. They are also strong, reliable and resistant to load.

a)

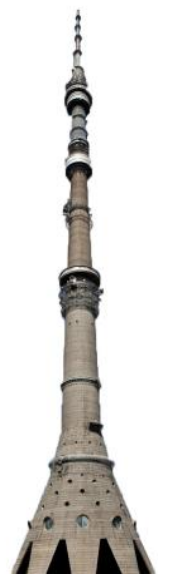

b)

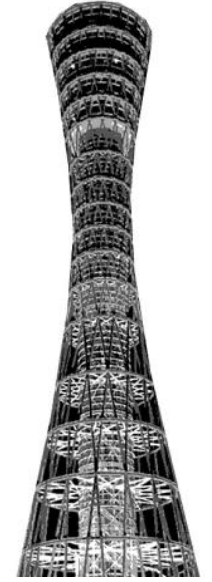

c)

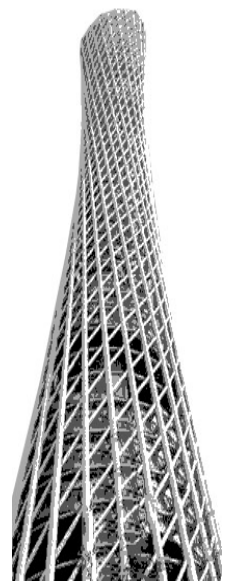

Fig. 6. TV towers with different structures: a) the use of cables and concrete; b) the combination of round mesh plates and hyperboloid of metal rods; c) mesh shell rotation.

In the design of roofs of structures such as stadiums, rod structures with shell coating were most often used (Fig. 7). Currently they began to apply designs that can move and open the sky, making this building an amazing from the point of view of architecture and more comfortable (Fig.7, a). In Rostov-on-Don, a flexible shell structure with a rigid frame along the contour of the roof (Fig. 8) was applied in the construction of "Rostov-Arena stadium. This became possible because of the creation of new materials and the search for an optimal solution for the coating of a long-span structure [13]. 
a)

b)
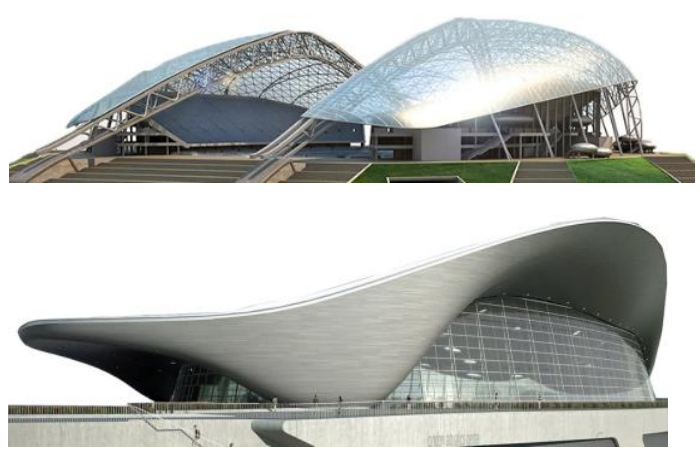

Fig. 7. Sports facilities built on the basis of bionic principles: a) "Fisht" stadium, Sochi, Russia; b) water sports stadium, UK.

a)

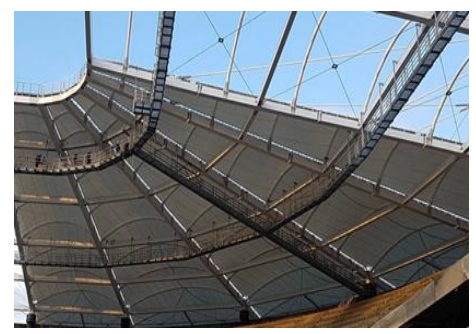

b)

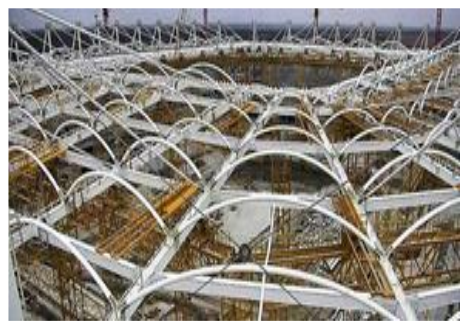

Fig. 8. "Rostov Arena" Stadium, Rostov-on-Don: a) flexible shell coating; b) metal frame of the stadium roof is held on cables.

Therefore, it is possible to define two main directions in bionics: architectural bionics and construction (or technical) bionics. Architectural bionics is a science that considers the possibility of creating architectural forms based on the study of natural objects, the distinctive feature of which is beauty, harmony, environmental friendliness, the use of natural materials, the unity of structures and the environment. Construction bionics studies the structure of natural objects (plants, animals, materials), which are characterized by rational forms of structure, optimal properties and processes of life. Modern bionics is based on the methods of mathematical modeling using modern software systems. The main objectives are to ensure reliability, optimal shape, energy savings, the use of new materials and a harmonious combination with the environment.

Architectural bionics enriches modern architecture. It is based on perfect samples of wildlife, using their patterns. We can highlight the main trends in the development of this science: bio- materials and components science, biotechnics, bionic architecture, bionic urbanism, green architecture, architectural bionic ecology, architectural transplantism and others. They penetrate each other, enriching their direction. In the future, new trends will emerge and develop in bionics. For example, let us consider one of the directions. Bionic architecture is the creation of projects that combine natural forms in building structures, constructions and the surrounding nature. Due to the development of this direction, unique structures appeared in the world (Fig. 9). 
a)

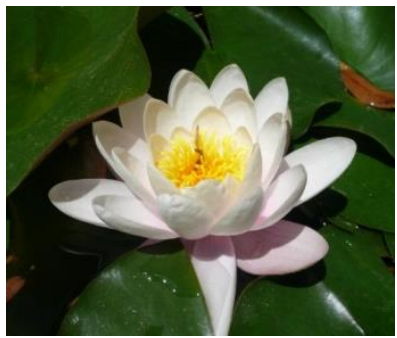

b)

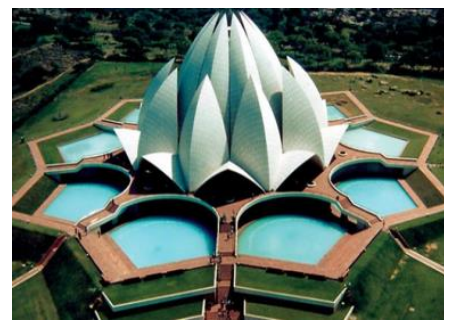

Fig. 9. Examples of bionic forms: a) Lotus flower; b) unique structure built on the basis of bionic principles (Bahai temple in New Delhi, India).

Architectural bionics considers the possibility of using the laws of nature in architectural structures, modern trends in solving the problems of shape and structure of constructions, technical support, beauty and harmony of architectural forms [14-15].

\section{Discussion and conclusions}

The relevance of the study of this topic is due to the processes taking place both in our country and in the world. The combination of bionic principles and optimization methods creates the basis for the development of new equipment and unique architectural structures. The future remains in the creative approach in the design, harmony of man and nature.

\section{References}

1. M. Kushner (AST, Moscow, 2016)

2. G. Trube (Architecture-C, Moscow, 2014)

3. P.P. Gnedich (Eksmo-Press, Moscow, 2012)

4. D. Villesenor (Rizzoli, New York, 2015)

5. V.D. Eremin, A.E. Fedchenko, Rostov-on-Don: Southern University IMBL, 99-101 (2018)

6. V.D. Eremin, A.G. Avdeeva, Rostov-on-Don: Southern University IMBL, 95-98 (2018)

7. I.A. Mayatskaya, B.M. Yazyev, S.B. Yazyeva, P.B. Kulinich, MATEC Web of Conferences SPbWOSCE-2016 106, 01031 (2017)

8. I.A. Mayatskaya, D.B. Demchenko, P.A. Shevtsov, Regional architecture and construction 2(27), 137-145 (2016)

9. I.A. Mayatskaya, Bulletin of Volgograd state University of architecture and construction. The series 'Construction and architecture 45(64), 27-36 (2016)

10. I.A. Mayatskaya, S.B. Yazyeva, N.I. Zakieva, A.P. Lapina, Materials Science Forum 931, 754-758 (2017)

11. I.A. Mayatskaya, S.B. Yazyeva, B.M. Yazyev, Construction and technogenic safety 9(61), 7-11 (2017)

12. I.A. Mayatskaya, S.B. Yazyeva, B.M. Yazyev, Construction and technogenic safety 12(64), 29-32 (2018)

13. I.A. Mayatskaya, D.B. Demchenko, A.E. Fedchenko, Pyatigorsk, NCFU, 60-64 (2017)

14. C. Mount, J. Deitch (Skira Rizzoli Publications, New York, 2013)

15. Material innovation: architecture (Thames \& Hudson Ltd, London, 2014) 